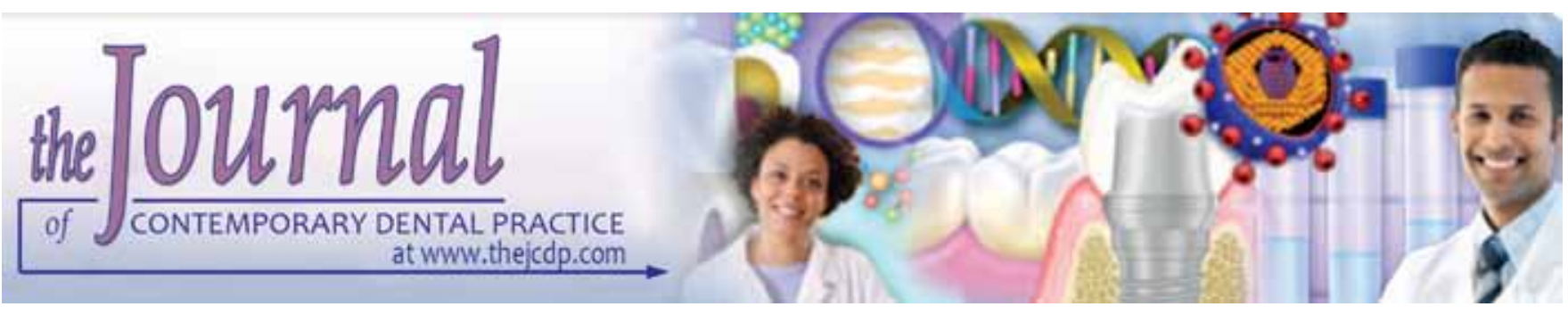

\title{
Dental Prosthetic Status and Prosthetic Needs of the Institutionalized Elderly Living in Geriatric Homes in Hyderabad: A Pilot Study
}

\author{
G Ajay Kumar, G Maheswar, S Malathi, K Sridevi, P Ratnakar, B Someshwar
}

\begin{abstract}
Introduction: To promote oral health among the elderly, we need to know their prosthetic status and prosthetic need. Hence, a survey of prosthetic status and need of elderly inmates of geriatric homes in Hyderabad was done.
\end{abstract}

Materials and methods: A cross-sectional study was undertaken, and 174 subjects aged 60 years and above were examined of which 103 were male and 71 were female $(59.2 \%$ males and $40.8 \%$ females). The oral examination of the study subjects was carried out using basic oral health surveys, WHO 1997 criteria.

Results: Majority of the subjects, $73(70.8 \%)$ males and 53 $(74.6 \%)$ females had no prosthesis. Only $4.6 \%$ had complete dentures and $21.1 \%$ had removable partial dentures and $10.9 \%$ had single/multiple bridges. Need for any prosthesis was $(83.5 \%)$ male and $63(88.7 \%)$ female subjects and nearly 82 . $8 \%$ subjects required one-unit prosthesis.

Conclusion: Dental prosthetic status of people living in geriatric homes is very poor and there is high unmet need for prosthetic care existed among the institutionalized elderly surveyed.

Keywords: Elderly, Geriatric homes, Prosthetic status, Prosthetic needs.

Key messages: A prevention based intervention programs to reduce early tooth loss is recommended and Oral health programs should be specially designed for these special group.

How to cite this article: Kumar GA, Maheswar G, Malathi S, Sridevi K, Ratnakar P, Someshwar B. Dental Prosthetic Status and Prosthetic Needs of the Institutionalized Elderly Living in Geriatric Homes in Hyderabad: A Pilot Study. J Contemp Dent Pract 2013;14(6):1169-1172.

\section{Source of support: Nil}

\section{Conflict of interest: None}

\section{INTRODUCTION}

Aging in humans refers to multidimensional process of physical, psychological and social change. ${ }^{1}$ With the discoveries in the field of medical science and the improvement of social conditions, the lifespan of an individual has increased. The proportion of older people is growing faster than of any other age group. Because of this, the 21 st century may be called as the 'era of population ageing'.

It is estimated that by the year 2025 , there will be about 1.2 billion people above the age of 60 years worldwide. ${ }^{2}$ It is predicted that the elderly population of India shall be the highest in the world by 2025 . Their contribution to the demographic profile is increasing every day. According to the 1991 census, the geriatric population constituted $6.3 \%$ of the total Indian population and it is expected to rise to $8.9 \%$ in the year 2016 and $21 \%$ by the year $2050.3,4$

Oral health can be considered as an indicator of general health and quality of life in geriatric patients. Among older people, oral health is generally perceived to be less than physical health. Oral diseases are progressive and cumulative. They become more complex over time. ${ }^{5,6}$ Poor oral health among older people has particularly been seen in a high level of tooth loss, dental caries experience and high prevalence rates of periodontal disease. ${ }^{7}$

Oral healthcare needs of the elderly those living in geriatric homes have been found to be significantly greater. ${ }^{8}$ The problems found in them are due to a lack of treatment facilities and information on morbidity profile and are less able financially to afford it. ${ }^{9}$

In this regard, loss of teeth in the elderly is a major concern. This tooth loss can lead to substantial impacts on quality of life. Restoration of missing teeth by appropriate prosthetic treatment is important for the rehabilitation of oral function, chewing ability, esthetic and maintenance of oral and general health.

The dental care among institutionalized elderly has been neglected. Hence the present study was planned to assess prosthetic status and needs among elderly residing in geriatric homes in Hyderabad. 


\section{MATERIALS AND METHODS}

This cross-sectional survey was conducted in FebruaryMarch 2012 to determine the prosthetic status and prosthetic need among the institutionalized elderly residing as inmates of Government aided geriatric homes in Hyderabad City, Andhra Pradesh State, India. All inmates aged 60 years and above formed the study population as, in India, this is the criterion for the classification of the elderly.

Before conducting the survey, the investigators visited the geriatric homes to meet the authorities in charge of these centers. Out of eight selected geriatric homes in the city, the authorities of six homes consented to the study.

\section{Inclusion Criteria}

All the elderly living in various geriatric homes in Hyderabad city.

\section{Exclusion Criteria}

- Study subjects not willing for examination.

- Study subjects with contraindication for examination.

- Nonambulatory/medically/psychologically compromised subjects who could not move out of their room for examination.

From the six geriatric homes, 174 inmates available at that time of study were included in the study population. ${ }^{11}$ Inmates were excluded from study as they were severely ill and noncoperative. The aim of the study was explained, their approval was sought and obtained, and the dates for the survey were fixed. Subjects had been informed of the nature of the investigation and had been included in the study after their consent was obtained.

A pretested proforma was used for data collection. It consisted of two parts- the 1st part recorded data on sociodemographic factors (age and gender), while the 2nd part contained a section of the World Health Organization (WHO) Oral Health Assessment Form $(1997)^{10}$ to record the prosthetic status and prosthetic need (i.e. denture wearing and need for dentures) of the elderly population.

The investigators were trained and calibrated in recording the proforma and the clinical findings, Standardization and calibration of the recorders was also achieved during the same sessions.

Subjects were examined seated in a chair or stool in open space under natural light, outside the home. The recorder was made to sit close to the examiner so that the instructions and codes could be easily heard and the examiner could see that findings are being recorded correctly.

\section{STATISTICAL ANALYSIS}

Data obtained were subjected to the Statistical Package for the Social Sciences (SPSS) Version 17.0. Data comparison was done by applying chi-square tests to find out the statistical significance of the comparisons. Significance level was fixed at $\mathrm{p}<0.05$.

\section{RESULTS}

A total of 174 subjects, 103 males (59.1\%) and 71 females, (40.8\%) aged 60 years and above (age range 60-97 years) formed the study population. The distribution of subjects according to age and gender is given in Table 1.

Table 2 shows the distribution of subjects according to their prosthetic status. Majority of the subjects $73(70.8 \%)$ male and 53 (74.6\%) female had no prosthesis. Single Bridge was found in 13 subjects and multiple bridges were found in 6 subjects. Subjects with partial were 12 male (11.6\%) and 9 (12.6\%) respectively. Full removable denture was seen

\begin{tabular}{llll}
\multicolumn{4}{c}{ Table 1: Age-wise and gender-wise distribution of study } \\
population
\end{tabular}

\begin{tabular}{llll}
\multicolumn{4}{c}{ Table 2: Distribution of subjects according to their prosthetic } \\
status \\
\hline Prosthetic status & Male (\%) & Female (\%) & Total \\
\hline No prosthesis & $73(70.9 \%)$ & $53(74.6 \%)$ & $126(72.4 \%)$ \\
Bridge & $9(8.7 \%)$ & $4(5.6 \%)$ & $13(7.5 \%)$ \\
More than one bridge & $4(3.9 \%)$ & $2(2.8 \%)$ & $6(3.4 \%)$ \\
Partial denture & $12(11.6 \%)$ & $9(12.7 \%)$ & $21(12.1 \%)$ \\
Full removable & $5(4.9 \%)$ & $3(4.2 \%)$ & $8(4.6 \%)$ \\
denture & & & \\
\hline Total & $103(100 \%)$ & $71(100 \%)$ & $174(100 \%)$ \\
$\chi^{2}$ & 0.83615 & & \\
df & 4 & & \\
p-value & $>0.05$ & & \\
\hline
\end{tabular}

\begin{tabular}{|c|c|c|c|}
\hline Prosthetic need & Male (\%) & Female (\%) & Total \\
\hline $\begin{array}{l}\text { Need for one unit } \\
\text { prosthesis }\end{array}$ & $39(37.9 \%)$ & $32(45.1 \%)$ & $71(40.8 \%)$ \\
\hline $\begin{array}{l}\text { Need for multi-unit } \\
\text { prosthesis }\end{array}$ & $26(25.2 \%)$ & 17 (23.9\%) & $43(24.7 \%)$ \\
\hline $\begin{array}{l}\text { Need for full } \\
\text { prosthesis }\end{array}$ & $21(20.4 \%)$ & 14 (19.7\%) & $35(20.1 \%)$ \\
\hline Total & $86(83.5 \%)$ & $63(88.7 \%)$ & $149(85.6 \%)$ \\
\hline$\chi^{2}$ & 0.43387 & & \\
\hline df & 2 & & \\
\hline$p$-value & $>0.05$ & & \\
\hline
\end{tabular}


in $5(4.8 \%)$ male and $3(4.2 \%)$ female subjects only. There was no statistically significant difference between prosthetic status and gender $(p>0.05)$.

Table 3 shows the number and percentage of subjects with prosthetic needs. Out of 174 residents, 86 (83.5\%) male and $63(88.7 \%)$ female subjects required prosthesis. One-unit prosthesis was required most $39(37.8 \%)$ male and $32(45 \%)$ female subjects, followed by need for multi-unit prosthesis and full removable prosthesis. Full removable dentures were required by $21(20.4 \%)$ male and $14(19.7 \%)$ female subjects. there was no statistically significant difference between prosthetic need and gender $(\mathrm{p}>0.05)$.

\section{DISCUSSION}

Very few studies have been conducted in India, pertaining to the prosthetic status and needs of people living in geriatric homes. No documented data was available for the institutionalized elderly of Hyderabad city. Therefore, an attempt was made to assess the prosthetic status and need of the residents of geriatric homes in hyderabad city.

In the present study majority of the subjects $73(70.8 \%)$ male and $53(74.6 \%)$ female had no prosthesis. Similar findings were reported by Shenoy and Hegde ${ }^{11}$ in Geriatric Homes in Mangalore where $88 \%$ had no prosthesis in upper and lower arch. Soh et $\mathrm{al}^{8}(1992)$ reported $78 \%$ subjects in long-term care facilities in Singapore were not having any denture. In contradiction studies by Hawkins et al $(1998)^{12}$ reported $80 \%$ of subjects wore at least one denture and Angelillo et al $(1990)^{13}$ reported $44.3 \%$ of the edentulous in both jaws wore complete dentures. Cardoso et al (2011) ${ }^{14}$ reported higher use of upper (79.2\%) and lower (37.1\%) total prostheses among the elderly people of Manaus city as a result of higher utilization of dental services by them.

In the present study the low proportion of those who had prostheses can be due to the fact that older people under use dental facilities due to lack of awareness, financial constraints and reduced mobility. ${ }^{11}$ The estimation of treatment need is an important stage in oral healthcare planning of elderly. Prosthetic need in the present study for $86(83.5 \%)$ male and $63(88.7 \%)$ female subjects respectively which was in accordance with $76 \%$ by Mann J et al (1985) ${ }^{15}$ in Israel and $72 \%$ by Shah et al $(2004)^{3}$ in India. Miyazaki et al $(1992)^{16}$ in Japan reported prosthetic need of 36\%.

The level of prosthetic need was higher in females 88.7 than males $83.5 \%$ but there was no statistically significant difference prosthetic need and gender $(p>0.05)$. This was in contradiction with a study conducted by Palmqvist $(1988)^{17}$ and Shah $(2004)^{3}$ where prosthetic treatment need for male and female elderly was significantly different and male has higher need for complete denture.
In the current study, the need for single-unit prostheses in $39(37.8 \%)$ male and 32 (45\%) female subjects was more than the need for multi-unit prostheses or full prostheses which was in accordance with the studies reported by Goel $\mathrm{P}$ et $\mathrm{al}^{18}$ and Christensen J. ${ }^{19}$ and in contrast with the study by Shenoy and Hegde (2010) ${ }^{11}$ in Mangalore where the need for multi-unit prostheses was more than the need for one-unit prostheses.

Higher prosthetic need among these institutionalized elderly may attribute to their old age. Factors associated with old age such as reduced salivary flow rate, quality and quantity, lowered immunity and the reduced ability of the body to repair itself may aggravate the process of degradation of the oral tissues. ${ }^{2}$ Although aging alone is not responsible for the deterioration of their oral health, several other factors such as multiple chronic diseases, socioeconomic factors, lack of dental facilities and psychological factors such as depression and isolation, because of gradual loss of spouse and friends and feeling of being unwanted by family members, leading to negligence of personnel and oral hygiene and health.

\section{CONCLUSION}

The findings of this study show that the dental prosthetic status of institutionalized older people living in geriatric homes is very poor and there is high percentage of unfulfilled prosthetic need. A wide gap was seen in between the prosthetic needs and prosthetic status.

Based on the present study findings, following are the recommendations:

- A prevention based intervention program to reduce early tooth loss is recommended for the residents of geriatric homes which includes regular oral health screenings and oral health education programs.

- Oral health programs should be specially designed for these special group and aim at empowerment and self care capacity building of older people and enhance their attitudes, knowledge and oral hygiene practices.

- Oral healthcare facilities should be availed to the residents by taking help from government, non-government agencies and private institutions.

\section{REFERENCES}

1. Bath PA. Differences between older men and women in the selfrated health-mortality relationship. Gerontologist 2003;43(3): 387-395; discussion 372-375.

2. Ngatia EM, Gathece LW, Macigo FG, Mulli TK, Mutara LN, Wagaiyu EG. Nutritional and oral health status of an elderly population in Nairobi. East African Medical Journal 2008 August;85(8):378-385. 
3. Shah N, Parkash H, Sunderam KR. Edentulousness, denture wear and denture needs of Indian elderly - a community-based study. J Oral Rehabil 2004;31:467.

4. Thakare V,Ajith Krishnan CG. Periodontal status, prostheticstatus and prosthetic needs among institutionalized geriatric individuals in Vadodara City, Gujarat-A descriptive study. J Ind Asso Public Health Dentistry 2010(15):153-157.

5. WHO: Important target groups. Available at: www.who.int/ oral_health/action/groups/en/index/html. cited on 06/09/11.

6. Bulletin of WHO: More oral health care needed for aging populations. Available at: www.who.int/entity/bulletin/ volume $/ 83 / 9 /$ - en/index.htm.

7. Gaiao LR, Almeida ME, Filho JG, Leggat P, Heukelbach J. Poor dental status and oral hygiene practices in institutionalized older people in Northeast Brazil. International Journal of Dentistry 2009:1-6. Article ID 846081.

8. Soh G, Chong YH, Ong G. Dental prosthetic status and needs of an elderly population living in long-term care facilities in Singapore. J Community Health 1992;17(3):175-181.

9. Karuza J, Miller WA, Lieberman D, Ledenyi L, Thines T. Oral status and resident well-being in a skilled nursing facility population. Gerontologist 1992;32(1):104-112.

10. World Health Organization, Oral Health Surveys-Basic Methods, World Health Organization, Geneva, Switzerland. 4th ed. 1997.

11. Shenoy RP, Hegde V. Dental prosthetic status and prosthetic need of the institutionalized elderly living in geriatric homes in Mangalore: A Pilot Study. International Scholarly Research Network 2011:1-3. Article ID 987126.

12. Hawkins RJ, Main PA, Locker D. Oral health status and treatment needs of Canadian adults aged 85 years and over. Spec Care Dentist 1998;18(4):164-169.

13. Angelillo IF, Sagliocco G, Hendricks SJ, Villari P. Tooth loss and dental caries in institutionalized elderly in Italy. Community Dent Oral Epidemiol 1990 Aug;18(4):216-218.

14. Cardoso EM, Parente RCP, Vettore MV, Rebelo MB. Oral health conditions of elderly residents in the city of Manaus. Rev Bras Epidemiol 2011;14(1):1-10.

15. Mann J, Mersel A, Gabai E. Dental status and dental needs of an elderly population in Israel. Community Dent Oral Epidemiol 1985 Jun;13(3):156-158.

16. Miyazaki H, Shirahama R, Ohtani I, Shimada N, Takehara T. Oral health conditions and denture treatment needs in institutionalized elderly people in Japan. Community Dent Oral Epidemiol 1992; 20(5):297-230.

17. Palmqvist S. Treatment needed and received in an elderly Swedish county population. Gerodontics 1988:4:272-276.

18. Goel P, Singh K, Kaur A,Verma M. Oral healthcare for elderly: Identifying the needs and easible strategies for service provision. Indian Journal of Dental Research 2006;17:11-21.

19. Christensen J. Oral health status of 65 to 75 years old Danes; A preliminary report of the replication of WHO's international collaborative study in Denmark. J Dent Res 1977;56:149-153.

\section{ABOUT THE AUTHORS}

\section{G Ajay Kumar}

Reader, Department of Prosthodontics, Army College of Dental Sciences, Secunderabad, Andhra Pradesh, India

Correspondence Address: H. No: 12-5-65/1, Flat No: 410, Sri Harsha Sethuram Unique Apartment, Vijayapuri Colony, Tarnaka Secunderabad-500017, Andhra Pradesh, India, Phone: 9885073469 e-mail: ajay_mds_prostho@yahoo.com

\section{G Maheswar}

Reader, Department of Oral and Maxillofacial Surgery, Meghna Institute of Dental Sciences, Nizamabad, Andhra Pradesh, India

\section{S Malathi}

Reader, Department of Oral Medicine and Radiology, Army College of Dental Sciences, Secunderabad, Andhra Pradesh, India

\section{K Sridevi}

Professor, Department of Oral Medicine and Radiology, SGT Dental College and Research Institute, Gurgaon, Haryana, India

\section{P Ratnakar}

Professor, Department of Oral Medicine and Radiology, Carrier Postgraduate Institute of Dental Sciences, Lucknow, Uttar Pradesh India

\section{B Someshwar}

Senior Lecturer, Department of Conservative Dentistry, Meghna Institute of Dental Sciences, Nizamabad, Andhra Pradesh, India 